\title{
Ion-Conductance and Solvation Behavior of Benzyl Trimethyl Ammonium Chloride in Aqueous-Methanol Mixtures
}

\author{
J. Sunil Kumar, V. Radhika, N. Srinivas, P. Manikyamba
}

\begin{abstract}
Ion-conductance and solvation conduct associated with diverse electrolytes in solvents is recited to be shaped by numerous aspects like density, viscosity, dielectric constant of medium, ion-solvent relations and solvent-solvent actions. Ion-solvent interactions soothe the ion by solvating it. Conductance statistics and viscosity numbers of distant electrolytes is of use in analyzing the ion solvent relations and solvation behavior of the ions. Conductance and ion-solvation behavior of benzyl trimethyl ammonium chloride has been measured in aqueous methanol and aqueous dimethyl formamide of different composition in the temperature range of $283 \mathrm{~K}$ to $318 K$. Limiting molar conductance dissociation constant of the ion pair, $K_{C}$ are figured using Fuoss-Kraus Limiting Law. $\lambda_{0}$ rise with percentage of water in the solvent fusion. $K_{C}$ value is highest in pure aqueous solvent. Walden product is highest in $20 \%$ aqueous-methanol mixture signifying that ion-solvent interactions are highest at this composition of solvent combination and Walden .product as a function of the specific ion-solvent interactions including structural effects.
\end{abstract}

Keywords : Benzyl trimethyl ammonium chloride, Free energy change, Aqueous-MEOH, Ion-solvation.

\section{INTRODUCTION}

Ion-conductance and solvation activities of various electrolytes in diverse solvent system is reported to persuade by numerous factors like density, viscosity, dielectric constant of the medium, ion-solvent connections and solvent-solvent connections. Ion-solvent connections soothe the ion by solvating it reported in text survey Manikyamba et al $^{1-10}$ indicate that, the conductance statistics and viscosity statistics of different electrolytes is helpful to study the ion solvent connections and solvation behavior of the ions. However, text is complete by such information; related text on benzyl trimethyl ammonium chloride is missing. In the resent report, observations on conductance behavior of benzyl trimethyl ammonium chloride in aqueous mixtures of methanol at different temperatures between 398 and $318 \mathrm{~K}$ studies are outlined.

Revised Manuscript Received on December 30, 2019.

* Correspondence Author

J. Sunil Kumar, Chemistry Department, S R Engineering College, Warangal Urban-506 371, INDIA. E--mail: suneelsrec@gmail.com

V. Radhika, Chemistry Department, S R Engineering College, Warangal Urban-506 371, INDIA. E-mail: suneelsrec@gmail.com

N. Srinivas, Chemistry Department, S R Engineering College, Warangal Urban-506 371, INDIA. E-mail: suneelsrec@gmail.com

P. Manikyamba, Chemistry Department, S R Engineering College, Warangal Urban-506 371, INDIA. E-mail: suneelsrec@gmail.com

(c) The Authors. Published by Blue Eyes Intelligence Engineering and Sciences Publication (BEIESP). This is an open access article under the CC BY-NC-ND license (http://creativecommons.org/licenses/by-nc-nd/4.0/)

\section{EXPERIMENT SECTION}

Deionzied water was refined and utilized. N, N-dimethyl formamide (DMF) (sd-fine chemicals) was used virtually. Benzyl trimethyl ammonium chloride (Spectrochem) sample is also utilized devoid of further purification. A conductivity meter (ELICO.Model - 180) outfitted with a glass conductivity cell of cell constant $0.9848 \mathrm{~cm}^{-1}$ was used to compute the conductance of the solution, Cell is calibrated using standard Saturated $\mathrm{KCl}$ solution. The precision of the conductivity bridge is $0.02 \mu \mathrm{S}$. A stock solution of $0.01 \mathrm{M}$ Benzyl trimethyl ammonium chloride was equipped in water / aqueous organic solvent mixtures of disparate composition $(\mathrm{v} / \mathrm{v})$ in the range 0 to $100 \%$ organic constituent. The solution was thinned to diverse concentrations using different volumes of solvent/ solvent mixture and the conductance values were calculated in the temperature range 298-318 K. Solvent / Solvent in the mixture used in these studies enclose conductance values in range $10-20 \mu \mathrm{S}$. Conductance of solvent was deducted to get conductance of the solute at each concentration. Molar conductance values calculated from the observed conductance are analyzed using Fuoss-Kraus limiting law ${ }^{11}\left(\mathrm{eq}^{\mathrm{n}} 1\right)$

$$
\frac{1}{\lambda}=\frac{\lambda C}{K_{C} \lambda^{0}}+\frac{1}{\lambda^{0}} \text {--.------ (1) }
$$

$\Lambda$ is molar conductance at concentration $\mathrm{C}, \lambda_{0}$ is limiting molar conductance. $\mathrm{K}_{\mathrm{C}}$ is dissociation constant. Least square analysis of using above equation (1) is acceptable with linear correlation coefficients within range 0.92-0.98.

\section{RESULT AND DISCUSSION}

Molar conductance ( $\Lambda$ ) was determined from solvent corrected specific conductance used for Benzyl tri methyl ammonium chloride in aqueous-methanol, in various compositions (v/v) of water - methanol mixtures at 298, 308, 313 and $318 \mathrm{~K}$. The values were analyzed by means of Debye - Huckel - Onsager, Fuoss - Kraus limiting law of conductivity to assess molar conductance at infinite dilution $\Lambda_{0}$. The values therefore obtained are revealed in Table-1. 
Ion-Conductance and Solvation Behavior of Benzyl Trimethyl Ammonium Chloride in Aqueous-Methanol Mixtures

Table- I: Molar conductance ( $\mathrm{mho} \mathrm{cm}^{2} \mathrm{~mol}^{-1}$ ), Dissociation constant $(\mathrm{Kc})$ values of Benzyl trimethyl ammonium chloride in binary aqueous-methanol organic mixtures.

\begin{tabular}{|c|c|c|c|c|c|c|c|c|}
\hline \multirow{2}{*}{ C } & \multicolumn{2}{|c|}{$298 \mathrm{~K}$} & \multicolumn{3}{c|}{$303 \mathrm{~K}$} & \multicolumn{3}{c|}{$313 \mathrm{~K}$} \\
\cline { 2 - 9 } & $\lambda_{k}^{0}$ & $\mathrm{~K}_{\mathrm{c}}$ & $\lambda_{k}^{0}$ & $\mathrm{~K}_{\mathrm{c}}$ & $\lambda_{k}^{0}$ & $\mathrm{~K}_{\mathrm{c}}$ & $\lambda_{k}^{0}$ & $\mathrm{~K}_{\mathrm{c}}$ \\
\hline 0 & 118.61 & 0.19 & 134.62 & 0.22 & 149.56 & 0.25 & 162.99 & 0.21 \\
\hline 20 & 92.70 & 0.15 & 106.42 & 0.17 & 115.80 & 0.17 & 125.06 & 0.17 \\
\hline 40 & 76.23 & 0.09 & 87.13 & 0.10 & 95.60 & 0.10 & 107.75 & 0.09 \\
\hline 60 & 70.60 & 0.08 & 79.27 & 0.10 & 82.83 & 0.12 & 91.16 & 0.11 \\
\hline 80 & 76.59 & 0.09 & 81.83 & 0.10 & 86.86 & 0.10 & 99.13 & 0.09 \\
\hline 100 & 78.96 & 0.11 & 90.46 & 0.11 & 94.36 & 0.11 & 102.70 & 0.11 \\
\hline
\end{tabular}

$\lambda_{k}^{0}=$ Fuoss-Kraus-Bray limiting law $\quad \mathrm{K}_{\mathrm{C}}=$ Dissociation constant from Kraus-Bray equation

Estimated values increase with rise in temperature in all cases owed to amplify in thermal energy and mobility of ions. Limiting molar conductance values are observed to be dependent on composition of the solvent also. At each temperature, these values are maximum in pure water. With the addition of methanol to water, they gradually decrease up to $60 \%$. The composition of methanol $80 \%($ $\mathrm{v} / \mathrm{v}$ ) to Benzyl trimethyl ammonium chloride again increase up to $100 \%$.

The decrease $\Lambda_{0}$ up to $60 \%$ is due to increase in the proportion of Methanol could be due to decline in the dielectric constant of medium. On addition of co-solvent to water, solvent - solvent interaction increased. Since conductivity increases by increase in temperature, it is thought that, this variation has to go after Arrhenius relation ${ }^{12}$ similar to rate process, $\Lambda_{0}=\mathrm{Ae}^{-\mathrm{Ea} / \mathrm{RT}}, \mathrm{E}_{\mathrm{a}}$ is energy of activation of rate process, $\mathrm{R}$ is gas constant and $\mathrm{T}$ is temperature on absolute scale. From slope of linear plot versus $\frac{1}{\mathrm{~T}}, \mathrm{E}_{\mathrm{a}}$ is evaluated. $\mathrm{E}_{\mathrm{a}}$ values are represented in Table-II. These values appear to be very much dependent on solvent mixture. In DMF-water, mixture $\mathrm{E}_{\mathrm{a}}$ value is maximum at $100 \%$ water.

Table-II: Activation Energy $\left(E^{\mathrm{a}}\right)$ Data in $\mathrm{KJ} \mathrm{mol}^{-1}$ values of Benzyl trimethyl ammonium chloride in binary aqueous-methanol organic mixtures.

\begin{tabular}{|c|c|}
\hline \% of organic component & Benzyl Trimethyl Ammonium Chloride \\
\hline 0 & 14.13 \\
\hline 20 & 14.37 \\
\hline 40 & 15.02 \\
\hline 60 & 10.66 \\
\hline 80 & 13.48 \\
\hline 100 & 11.25 \\
\hline
\end{tabular}

\section{CONCLUSION}

The conclusion from these experimental observations that ion-ion interactions are strong in higher percentage of $60 \%$ aqueous-methanol.

\section{ACKNOWLEDGMENT}

The author wishes to thank anonymous support given by S R Engineering College, Ananthasagar, Hasanparthy (V), Warangal Urban, India.

\section{REFERENCES}

1. V. Radhika \& P.Manikyamba, "Conductance and Solvation Behavior of Quinolinium Dichromate in Binary Mixtures of Water with, N-Dimethyl Formamide", 2008, J.Chem.Eng. Data 53, pp. 2766-2769

2. V. Radhika \& P.Manikyamba, "Ion-solvation behavior of pyridinium dichromate in water - N, N- dimethyl formamide mixtures", 2012, Journal of solution Chemistry, 41, pp. 261-270.

3. V. Radhika \& P.Manikyamba, "Conductivity studies on solvation and computational work of onium ions in aqueous-dimethyl sulphoxide mixtures.” 2012, European J. of Chemistry. 3 (1), pp. 71-74.

4. V. Radhika \& P.Manikyamba, "Solvation of quinolinium dichromate in aqueous-dimethyl sulphoxide mixture studied by viscosity and conductance." 2012, National academy of Sciences, Sect.A, 82(2), pp. 137-141. 
5. V. Radhika, \& P.Manikyamba, "ION-ASSOCIATION AND ION-SOLVATION BEHAVIOR OF METHY, PHENYL AND BENZYL TRIMETHYL AMMONIUM CHLORIDE IN DMSO-WATER MIXTURES AT 298K", 2019, Rasayan J. Chem., 12(4), pp. 1816 - 1821.

6. V. Radhika, "Ion- Solvation Behavior of Heterocyclic Dichromates in Aq-Organic Solvent Mixtures", 2019, National academy of Sciences, Sect.A,http://doi.ogg/10.007/s 400100-019-00624-5, pp. online published.

7. V. Radhika \& P.Manikyamba, "Conductance and Solvation behavior of benzimidazolium dichromate in dimethyl sulphoxide - water mixtures", 2008, Indian journal of Chemistry, 47A, pp. 1814-1817

8. V.Radhika \& P.Manikyamba, "Conductance and Ion-Solvation behavior of Sodium Sulfonates in aqueous-organic mixture", 2018, International Journal of Engineering Science Invention (IJESI), 7(5), pp. 36-42.

9. V. Radhika,"Conductance Study of Benzyl Bromide Reaction with Cyclic amines in Aqueous-Ethanol Medium", 2018, International Journal of Engineering \& Technology (IJESI), 7(303), pp. 138-140

10. John OM, Bockris, \& Amulya K N, Reddy, "Modern Electro Chemistry (Plenum, New York)", 1970

11. Glasstone S, "An introduction to Electro Chemistry (Van Wostrand)", 1965, (Vol.61)

\section{AUTHORS PROFILE}

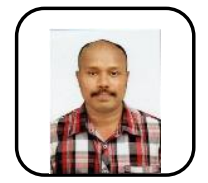

J. Sunil Kumar, M.Sc. Chemistry, 5 publications, 15 years teaching experience.

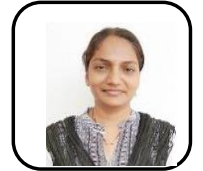

Dr.V.Radhika M.Sc. Chemistry, PhD, 28Journal Publications, 34 Conferences, 17 years teaching experience and one major research project. 